\title{
Summer High Temperature Extremes over China Linked to the Pacific Meridional Mode
}

\author{
MING LUO \\ School of Geography and Planning, and Guangdong Key Laboratory for Urbanization and Geo-simulation, Sun Yat-sen \\ University, Guangzhou, and Institute of Environment, Energy and Sustainability, The Chinese University of Hong Kong,
} Hong Kong, China

NGAR-CHEUNG LAU

Institute of Environment, Energy and Sustainability, The Chinese University of Hong Kong, Hong Kong, China

\author{
WEI ZHANG
}

IIHR-Hydroscience and Engineering, University of Iowa, Iowa City, Iowa

\section{QIANG ZHANG}

Key Laboratory of Environmental Change and Natural Disaster of Ministry of Education, State Key Laboratory of Earth Surface Processes and Resource Ecology, and Academy of Disaster Reduction and Emergency Management of Faculty of Geographical Science, Beijing Normal University, Beijing, China

\author{
ZHEN LIU \\ Institute of Environment, Energy and Sustainability, The Chinese University of Hong Kong, Hong Kong, China
}

(Manuscript received 10 June 2019, in final form 25 February 2020)

\begin{abstract}
This study investigates the association between summer high temperature extremes (HTEs) over China and the Pacific meridional mode (PMM) that is characterized by an anomalous north-south sea surface temperature gradient and an anomalous surface circulation over the northeastern subtropical Pacific. It is found that the HTE activities over most parts of southern China (particularly eastern China) are prominently intensified during the positive PMM phase and weakened during the negative phase. Further examinations suggest that the PMM is linked with HTEs in China through processes that entail both eastward and westward development of signals emanating from the PMM site. The westward development is associated with the formation of an anomalous low-level cyclone over the western North Pacific (WNP), which may be viewed as a Matsuno-Gill-type response to the off-equatorial heating in the eastern Pacific. This circulation change is accompanied by anomalous ascent over WNP and northern China, and subsidence over eastern China. On the other hand, the eastward development process is linked to the PMM-induced displacement of the East Asian jet stream and the generation of a midlatitude Rossby wave train. In the positive PMM phase, the above circulation changes are accompanied by anomalous air subsidence and enhanced adiabatic heating, reduced precipitation, anomalous lower-level anticyclone, and rising surface pressure over the eastern part of China. Moreover, the land surface of that region receives more solar radiation. Opposite changes are discernible over northern China. These changes are favorable for the occurrence and persistence of HTEs over eastern China and tend to suppress HTEs over northern China.
\end{abstract}

\section{Introduction}

High-temperature extremes (HTEs) pose disastrous impacts on human society and ecosystems. These events

Corresponding author: Ming Luo, luo.ming@hotmail.com have been occurring with increasing frequency, duration, and amplitude in many parts of the world under global warming and possibly regional urbanization (Meehl and Tebaldi 2004; IPCC 2012, 2013; Luo and Lau 2017). Due to the increasingly severe influences of HTEs, their characteristics and associations with 
atmospheric and oceanic patterns have received increasing attention in recent decades. Particularly, the long-term secular trends in HTEs have been extensively documented in the literature (Meehl and Tebaldi 2004; Fischer and Knutti 2015; Zhou et al. 2016; Luo and Lau 2017).

Recently, the HTE characteristics in China have been extensively studied (Lu and Chen 2016; You et al. 2017), with particular attention paid to the long-term trends and synoptic behavior (e.g., Freychet et al. 2017; Luo and Lau 2017). The intensifying trends in HTEs have been found in most parts of China, and they are especially prominent in the North China Plain, as well as the Yangtze and Pearl River deltas (Zhai and Pan 2003; Zhou and Ren 2011; Zhou et al. 2016; Yang et al. 2017). Examinations on the synoptic- and large-scale circulations show that the HTEs in many parts of China are accompanied by increases in surface pressure and solar radiation, and decreases in humidity, cloud, and precipitation (Ding et al. 2010; Lu and Chen 2016; Luo and Lau 2017). During HTE events, the areas are also covered by anomalously warm, dry, and subsiding air columns. It has been suggested that the occurrence of HTEs in southern and eastern China are associated with the westward extension of the western North Pacific (WNP) subtropical high (WNPSH), as characterized by increased geopotential height and enhanced WNP anticyclone (over around $10^{\circ}-20^{\circ} \mathrm{N}, 120^{\circ}-150^{\circ} \mathrm{E}$ ) covering southeastern China (Ding et al. 2010; Luo and Lau 2017).

The interannual variabilities of HTEs in China have also been investigated, with the goal of improving the prediction skill for such extreme events. For instance, $\mathrm{Hu}$ et al. (2012) reported that the frequency of late summer HTEs in the southern Yangtze River valley is influenced by the Indian Ocean basin mode. It has been suggested that the interannual variations of HTEs in southeastern China are related to the East Asian jet stream (EAJS), the circumglobal teleconnection (CGT) pattern, and the relationship between the East Asian summer monsoon (EASM) and El Niño-Southern Oscillation (ENSO) (Wang et al. 2013, 2014; Luo and Lau 2018). ENSO greatly contributes to the interannual variations in East Asian climate (e.g., Chang et al. 2000; Wang et al. 2000; Wu and Wang 2002; Lau and Nath 2006; Zhou and Chan 2007; Li et al. 2010; Xie et al. 2010; Gao et al. 2020a). It can also have an intensifying effect on HTEs in China, possibly via the intensification of WNPSH (Hu et al. 2012, 2013; Chen et al. 2018; Luo and Lau 2018, 2020; Gao et al. 2020b).

In addition to the zonal mode in the tropical Pacific (i.e., ENSO), the Pacific meridional mode (PMM) has also been identified in the tropical and subtropical eastern Pacific Ocean by Chiang and Vimont (2004).
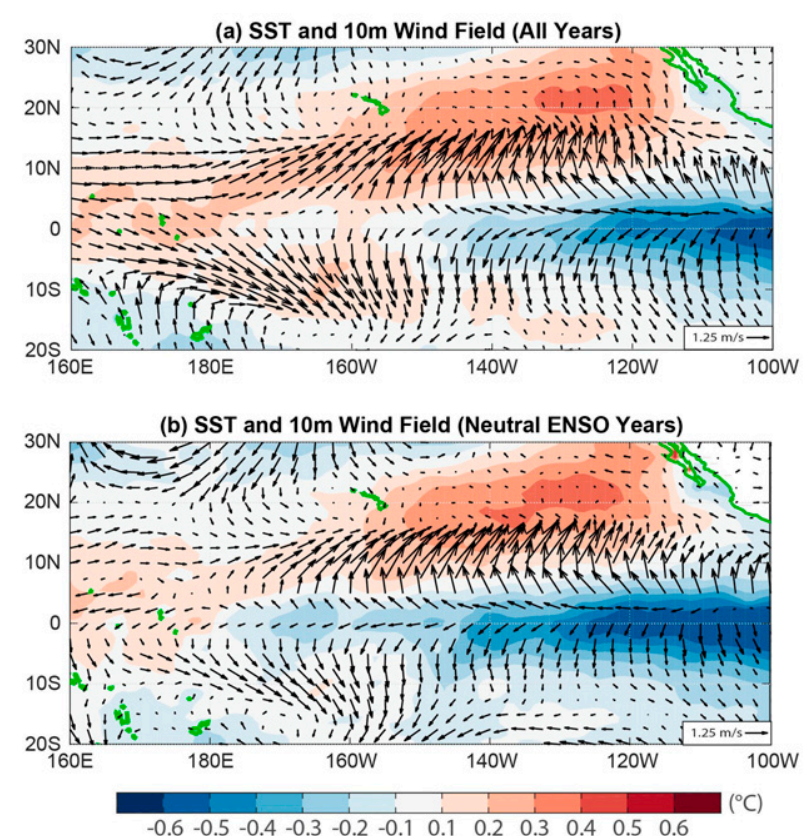

FIG. 1. The regression of SST and 10-m wind fields during (a) 1961-2018 and (b) neutral ENSO years during 1961-2018 onto the standardized PMM index in June-August. The spatial domain is similar to that in Chiang and Vimont (2004).

During the positive PMM phase (see Fig. 1), positive sea surface temperature (SST) anomalies prevail in the northwestern part, while negative SST anomalies appear in the southeastern part (Chiang and Vimont 2004). An analogous meridional mode is also observed in the South Pacific (Zhang et al. 2014a,b). The PMM is found to be forced by the North Pacific Oscillation (NPO), a teleconnection pattern characterized by a north-south seesaw in sea level pressure over the North Pacific (Walker and Bliss 1932; Rogers 1981). Ding et al. (2019) also demonstrated that the North American dipole (NAD) is intimately linked to the development of PMM. Previous studies suggest that there is also a close association between the PMM and ENSO (Chang et al. 2007; Zhang et al. 2009; Larson and Kirtman 2014; Thomas and Vimont 2016; Ma et al. 2017; Stuecker 2018; Amaya 2019).

The PMM is a precursor of ENSO (e.g., Chang et al. 2007; Larson and Kirtman 2014). Both model simulation and observations suggest that the PMM can affect ENSO events via the wind-evaporation-SST feedback mechanism (Zhang et al. 2009; Min et al. 2017; Thomas and Vimont 2016). The PMM and ENSO can jointly act to induce the decadal variability in the North Pacific (Di Lorenzo et al. 2015). The PMM can also occur independently of ENSO. Although both the PMM and ENSO may affect regional climate via atmospheric teleconnections, the impacts due to the PMM may be 
different from those due to ENSO (Chiang and Vimont 2004; Zhang et al. 2009). For instance, the WNP anticyclone tends to be stronger during El Niño decaying phases while a positive PMM induces a weakened WNP anticyclone (Zhang et al. 2016, 2017). The positive PMM phase favors the occurrence of TCs in the WNP (Zhang et al. 2016; Gao et al. 2018), which is different from the ENSO effects; that is, the TC activities in the WNP tend to be weaker (stronger) during El Niño (La Niña) decaying years (Chan 2000). Besides, Li et al. (2011) reported that PMM could profoundly affect the summer rainfall in the Yangtze River loop valley region of China, possibly via the trigger of an eastwardpropagating Rossby wave.

In view of the impacts of PMM on the Asia-Pacific sector as discussed above, we speculate that PMM may also have a close association with the summer temperature changes over China. Particularly, it is of great interest to investigate the possible associations between PMM and HTEs in China, which has not been studied in the literature. Such investigations are expected to enhance the understanding of HTEs in China and to provide valuable insights into the prediction of these extreme events. The rest of the paper is organized as follows. Section 2 introduces the datasets and methods used in this study. The analysis results are presented and discussed in section 3. Section 4 summarizes the main findings.

\section{Data and methods}

\section{a. Data}

In this study, we use a newly homogenized historical 2-m temperature dataset spanning from 1961 to 2018, as provided by the China Meteorological Data Service Center at http://data.cma.cn. The raw data have been homogenized using a method as described by $\mathrm{Xu}$ et al. (2013). We exclude the stations that have more than three missing days in any three or more summer seasons [June-August (JJA)] during 1961-2018. A total of 596 stations in the mainland of China are thus retained for subsequent analyses.

The PMM pattern is defined as the first maximum covariance analysis (MCA) mode of SST and 10-m wind fields in the tropical and subtropical eastern Pacific Ocean after removing the ENSO signal as represented by the cold tongue index (Chiang and Vimont 2004). The monthly PMM index is obtained from the NOAA Earth System Research Library, available at https:// www.esrl.noaa.gov/psd/data/timeseries/monthly/PMM/ (Chiang and Vimont 2004). For each year, the PMM index is calculated by averaging the monthly PMM SST index over the summer season (i.e., JJA), consistent with the previous study (Zhang et al. 2017). The SST data on a $1^{\circ} \times 1^{\circ}$ latitude-longitude grid are obtained from sea ice and sea surface temperature (HadISST) dataset produced by the Met Office Hadley Centre, as reconstructed using a two-stage reduced-space optimal interpolation procedure (Rayner et al. 2003).

In addition, the NCEP-NCAR Reanalysis-1 dataset (Kalnay et al. 1996) is used to examine the atmospheric patterns underlying the association between PMM and HTEs in China. The dataset is provided by the NOAA/ OAR/ESRL PSD, Boulder, Colorado, from their website at https://www.esrl.noaa.gov/psd/. Note that the results based on the NCEP-NCAR Reanalysis-1 dataset are generally consistent with those based on JRA-55 (Japan Meteorological Agency 2013; Kobayashi et al. 2015), and we only show the results from the NCEPNCAR Reanalysis-1 dataset. Monthly precipitation is obtained from the NOAA Precipitation Reconstruction Dataset (PREC) (Chen et al. 2002).

\section{b. Methods}

In this study, HTEs are independently identified for each station across China. An HTE at a station is defined when its daily maximum temperature $T_{\max }$ exceeds the 90th-percentile value of all daily $T_{\max }$ values in the summer seasons (JJA) of the reference period of 196190. The period of 1961-90 has been suggested by the Expert Team for Climate Change Detection and Indices (ETCCDI) and has been widely used in analyzing climate extremes (e.g., Alexander et al. 2006; Donat et al. 2013; Wang et al. 2014). The definition of HTE here is the same as that in Wang et al. (2014), and using this definition we obtain the total numbers of HTE days in all individual summers of 1961-2018. To test the robustness of the results, we also examine the results based on daily minimum temperature $T_{\text {min }}$; that is, HTE is defined when $T_{\min }$ exceeds its 90 th percentile. It is noticed that the results for $T_{\min }$ are very similar to those for $T_{\text {max }}$; therefore, we present the results derived from $T_{\text {max }}$ in this paper.

The anomalies for related atmospheric variables are also calculated by removing the climatological mean over the summer seasons of 1961-90. The long-term trend in these variables and the frequency of HTE in China are removed by simple linear regression. We then calculate the regression coefficient of the detrended HTE series at all stations across China onto the standardized PMM index for selected neutral ENSO years with low or no ENSO activity (see below). The atmospheric patterns underlying the PMM-HTE association are also examined by regressing the related atmospheric variables onto the standardized PMM index. 
The regression analysis is conducted on all grid points (or weather stations). The regression coefficient of atmospheric variables onto the PMM index at each grid point (or a station) can then be plotted as a spatial map (i.e., regression map), which shows the changes in a related variable in response to the PMM. In particular, given a dependent variable $Y$ (i.e., HTE frequency and other related variables such as winds) and an independent variable $X$ (i.e., the PMM index), the linear regression of $Y$ onto $X$ can be expressed as

$$
Y=\beta_{1} X+\beta_{0}+\varepsilon .
$$

In this statistical model, $\beta_{1}$ is the regression coefficient that measures the dependence of $Y$ on $X$ (i.e., the amount by which the dependent variable $Y$ increases when the independent variable $X$ is increased by one unit); $\beta_{0}$ is the constant, and $\varepsilon$ is the residual. The significances of regression and correlation coefficients are evaluated by bootstrapping with 1000 times sampling (Efron and Tibshirani 1994). We also use the Student's $t$ test to assess the significance and find that the results based on the bootstrap and Student's $t$ test methods are nearly the same (not shown).

To minimize the possible influences by ENSO events, we exclude the summers that follow a strong El Niño or La Niña event in the previous winter, as suggested by Chiang and Vimont (2004). El Niño and La Niña events are defined as the Niño-3.4 index in five consecutive overlapping 3-month periods above $0.5^{\circ}$ and below $-0.5^{\circ} \mathrm{C}$, respectively (Trenberth 1997; https://origin.cpc.ncep.noaa.gov/ products/analysis_monitoring/ensostuff/ONI_v5.php), and a strong ENSO event is defined when the index exceeds $1^{\circ} \mathrm{C}$ for at least three consecutive months (Chiang and Vimont 2004). This leaves 35 "neutral" ENSO years in the subsequent examination. Note that we also examine the results of using $0.5^{\circ} \mathrm{C}$ as the threshold to exclude all El Niño and La Niña events, which allows only 18 "pure" years for analysis, and we find that the results are highly consistent with those based on using $1.0^{\circ} \mathrm{C}$ as the threshold. To allow more cases for statistical analysis, in the following investigation (unless otherwise stated), we present the results for neutral ENSO years with low or no ENSO activity by excluding extreme ENSO events.

To further examine whether the PMM-HTE association is dependent on the influence of ENSO events, we also calculate the partial correlation between summer PMM and HTE frequency by removing the control of the preceding winter (December-February) Niño-3.4 index for neutral ENSO years. The partial correlation between two variables $X$ and $Y$ with the effect of controlling variable $Z$ removed is given by

$$
\rho_{X Y \cdot Z}=\frac{\rho_{X Y}-\rho_{X Z} \rho_{Y Z}}{\sqrt{1-\rho_{X Z}^{2}} \sqrt{1-\rho_{Y Z}^{2}}},
$$

where $\rho_{X Y}$ denotes the correlation coefficient between $X$ and $Y$, and $\rho_{X Z}$ and $\rho_{Y Z}$ are the correlations of $Z$ with $X$ and $Y$, respectively.

The wave activity flux (WAF) is examined to reveal the energy propagation pathways of the PMM-HTE association. WAF is a helpful diagnostic tool for detecting the propagation, source, and sink of a propagating packet of a stationary or migratory quasi-geostrophic wave disturbance (Takaya and Nakamura 2001). It is calculated at the 250-hPa level according to Takaya and Nakamura (2001):

$$
\mathbf{W}=\frac{p \cos \varphi}{2|\mathbf{U}|}\left\{\begin{array}{c}
\frac{U}{a^{2} \cos ^{2} \varphi}\left[\left(\frac{\partial \psi^{\prime}}{\partial \lambda}\right)^{2}-\psi^{\prime}\left(\frac{\partial^{2} \psi^{\prime}}{\partial \lambda^{2}}\right)\right]+\frac{V}{a^{2} \cos \varphi}\left[\frac{\partial \psi^{\prime}}{\partial \lambda} \frac{\partial \psi^{\prime}}{\partial \varphi}-\psi^{\prime} \frac{\partial^{2} \psi^{\prime}}{\partial \lambda \partial \varphi}\right] \\
\frac{U}{a^{2} \cos \varphi}\left[\frac{\partial \psi^{\prime}}{\partial \lambda} \frac{\partial \psi^{\prime}}{\partial \varphi}-\psi^{\prime} \frac{\partial^{2} \psi^{\prime}}{\partial \lambda \partial \varphi}\right]+\frac{V}{a^{2}}\left[\left(\frac{\partial \psi^{\prime}}{\partial \varphi}\right)^{2}-\psi^{\prime}\left(\frac{\partial^{2} \psi^{\prime}}{\partial \varphi^{2}}\right)\right] \\
\frac{f_{0}^{2}}{N^{2}}\left\{\frac{U}{a \cos \varphi}\left[\frac{\partial \psi^{\prime}}{\partial \lambda} \frac{\partial \psi^{\prime}}{\partial z}-\psi^{\prime} \frac{\partial^{2} \psi^{\prime}}{\partial \lambda \partial z}\right]+\frac{V}{a}\left[\frac{\partial \psi^{\prime}}{\partial \varphi} \frac{\partial \psi^{\prime}}{\partial z}-\psi^{\prime} \frac{\partial^{2} \psi^{\prime}}{\partial \varphi \partial z}\right]\right\}
\end{array}\right\}
$$

where $\mathbf{W}$ denotes the WAF (units: $\mathrm{m}^{2} \mathrm{~s}^{-2}$ ) and $p$ is pressure; $\psi$ is the streamfunction; $\mathbf{U}=(U, V)$ is horizontal wind vector, with $U$ and $V$ denoting the zonal and meridional wind components, respectively; $\lambda$ and $\varphi$ are longitude and latitude, respectively; $f_{0}$ is the Coriolis parameter; $N^{2}$ is the Brunt-Vaisala frequency; $a$ is Earth's radius; and the prime represents the anomaly.

\section{Results}

\section{a. Association between the PMM and HTEs in China}

The spatial patterns of SST and surface 10-m wind associated with the PMM are shown in Fig. 1, in which the regression coefficients of seasonal SST and 10-m wind onto the JJA PMM index are plotted for all years 
(a) Regression of HTE onto PMM

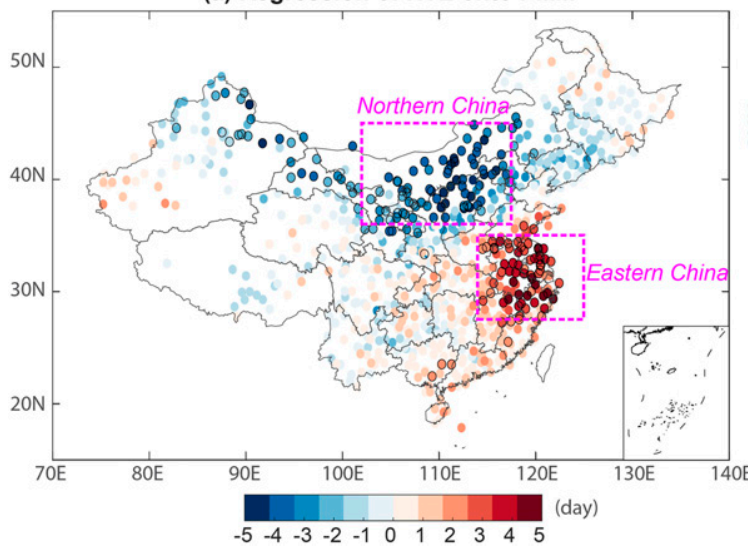

(b) Time series of PMM and HTE

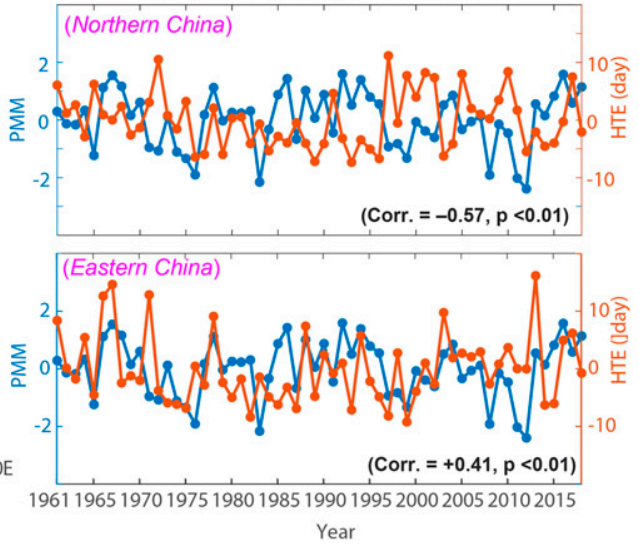

FIG. 2. (a) Regression of summer HTE frequency onto the standardized PMM index for neutral ENSO years during 1961-2018, with black-outlined circles denoting significance at the 0.05 level and dashed boxes indicating the domains of eastern and northern China. (b),(c) Time series of the PMM index and the HTE frequency averaged in northern and eastern China, respectively, during 1961-2018.

(Fig. 1a) and neutral ENSO years (Fig. 1b). There is a characteristic feature of the PMM in the eastern Pacific Ocean, with anomalous warming SST in the northwestern subtropical part and cooling in the southeastern tropical part. Strong southerly atmospheric flow appears in the northern deep tropical ocean, consistent with the strong SST gradient. Figure 1 also shows that the PMM during all years of 1961-2018 (Fig. 1a) exhibits similar SST and wind patterns to those during neutral ENSO years (Fig. 1b), indicating that ENSO marginally influences the PMM pattern.

Figure 2a depicts the regression of the yearly time series of the frequency of summer HTEs in China onto the standardized PMM index for neutral ENSO years. It shows that HTEs in most parts of China, except for northern China (around $36^{\circ}-45^{\circ} \mathrm{N}, 102.5^{\circ}-117.5^{\circ} \mathrm{E}$; see Fig. 2a), are more frequent during the positive PMM phases and less frequent during negative phases. This relationship is particularly strong in eastern China, that is, within $27.5^{\circ}-35^{\circ} \mathrm{N}$ and east of $114^{\circ} \mathrm{E}$ (as denoted by the rectangular box in Fig. 2a). The HTEs in northern China are less frequent during the positive PMM phase and more frequent during the negative phase. We also examine the regression map of the HTE frequencies in China onto the PMM index for all years (not shown) and note that the result with only neutral years essentially reproduces a similar pattern as the previous analysis using all years of the study period.

To further delineate the relationship between the PMM and HTE, we calculate the correlation coefficients between the time series of the summer PMM and HTE frequency averaged in eastern and northern China for neutral ENSO years (see Fig. 2b). The correlation coefficient between the PMM and HTEs in eastern China reaches +0.41 , with a $95 \%$ confidence interval (CI) from 0.12 to 0.65 based on 1000-times bootstrap sampling. The correlation between the PMM and HTEs in northern China is -0.57 , with a $95 \%$ CI from -0.75 to -0.3 . These results further demonstrate a close relationship between the PMM and summer HTE activity in China. It is also noted that these correlation coefficients of the summer PMM are especially stronger than the correlation of the spring (March-May) PMM with summer HTEs in eastern and northern China (i.e., +0.02 and -0.29 , respectively).

To examine whether the association of HTE with the PMM is independent of that with the ENSO events, the scatterplots of the PMM against HTE in eastern and northern China during neutral years with low or no ENSO activity are examined (Fig. 3). These diagrams show that the linear fitting lines during neutral-ENSO years are even steeper than that during all years of 19612018. Moreover, the partial correlation between the PMM and HTE in eastern (northern) China for neutral ENSO years by controlling the effect of the Niño-3.4 index is $0.41(-0.56)$, with $95 \%$ CI from 0.11 to 0.67 $(-0.75$ to -0.32$)$. These results demonstrate a close association between PMM and more frequent HTEs in eastern China and less frequent HTEs in northern China.

To quantify the impacts of the PMM on HTEs, we compare the differences in HTEs during positive and negative PMM phases (Fig. 4), which are defined when the summer PMM index exceeds its mean \pm 0.5 standard deviation (with extreme ENSO years excluded; see section $2 \mathrm{~b}$ ). Profound differences are observed in eastern China (Figs. 4a,c). The mean frequencies of detrended HTE frequency in this area during the positive and negative phases of the PMM are +2.06 and -5.16 days, 
(a) PMM versus HTE in Eastern China

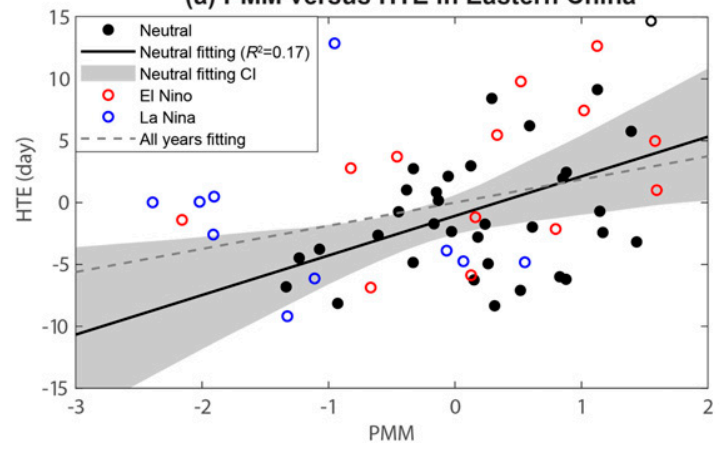

(b) PMM versus HTE in Northern China

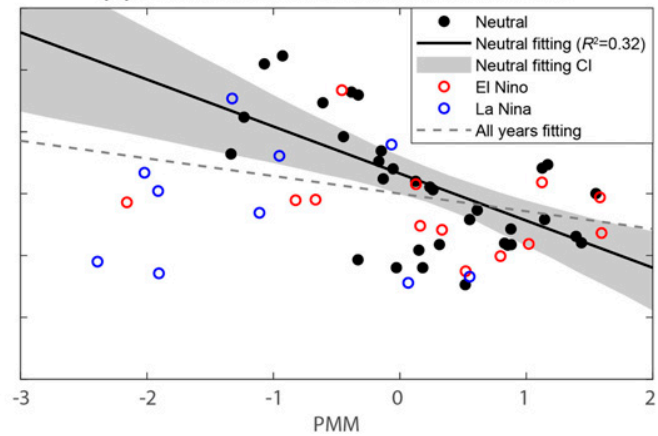

FIG. 3. Scatterplots of PMM vs HTE frequency in (a) eastern and (b) northern China during El Niño (red circles), La Niña (blue circles), and neutral ENSO years (black dots). The fitted lines are computed using data for all years in 1961-2018 (dashed line) and neutral ENSO years (thick solid line). Shading indicates the $95 \%$ bootstrap confidence interval (CI) based on 1000-times sampling. $R^{2}$ denotes the determination coefficient of linear regression. All fitted lines are significant at the 0.05 level based on 1000-times bootstrap sampling.

respectively. The differences in HTE days are relatively larger in northern China (Figs. 4b,d), and there are 1.68 fewer HTE days during positive PMM phases and 7.68 more days during negative phases. Based on the bootstrap method, we note that the mean differences of the PMM in both eastern and northern China between positive and negative PMM phases are all significant at the 0.05 level. (a) HTE Boxplot | Eastern

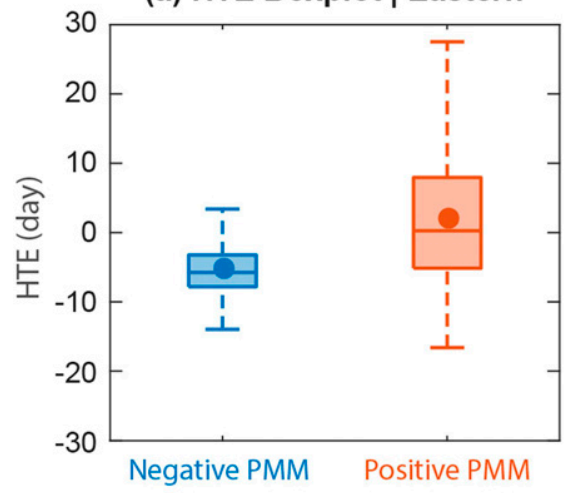

(c) HTE PDF | Eastern

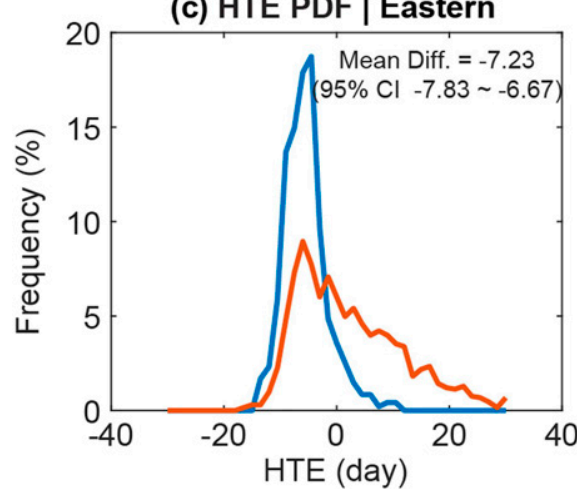

(b) HTE Boxplot | Northern

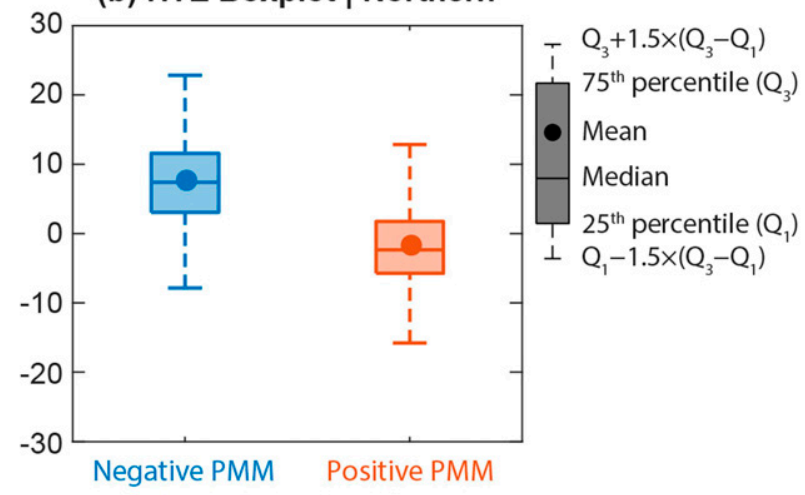

(d) HTE PDF | Northern

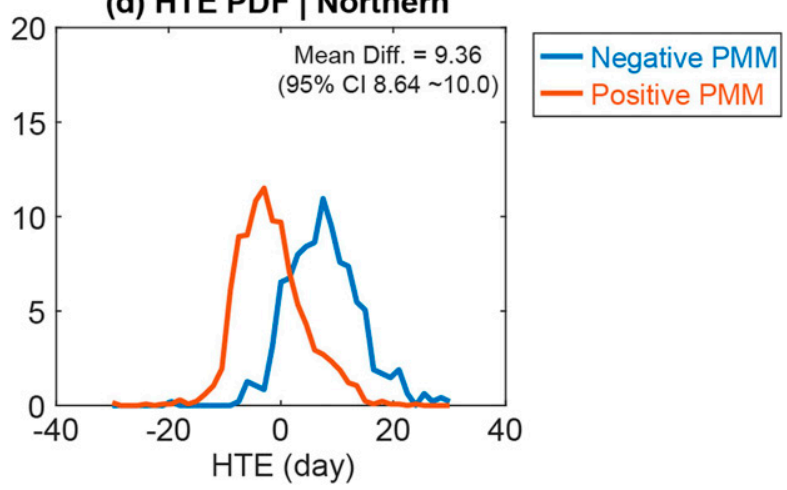

FIG. 4. (a),(b) Boxplots and (c),(d) probability distribution functions (PDFs) of the detrended HTE frequencies in (left) eastern and (right) northern China during positive (red) and negative (blue) PMM phases. The dots in (a) and (b) indicates the corresponding average. Definitions of various plotting symbols in (a) and (b) are illustrated at the upper-right corner of the figure. The $95 \%$ CIs in (c) and (d) are based on 1000-times bootstrap sampling. 

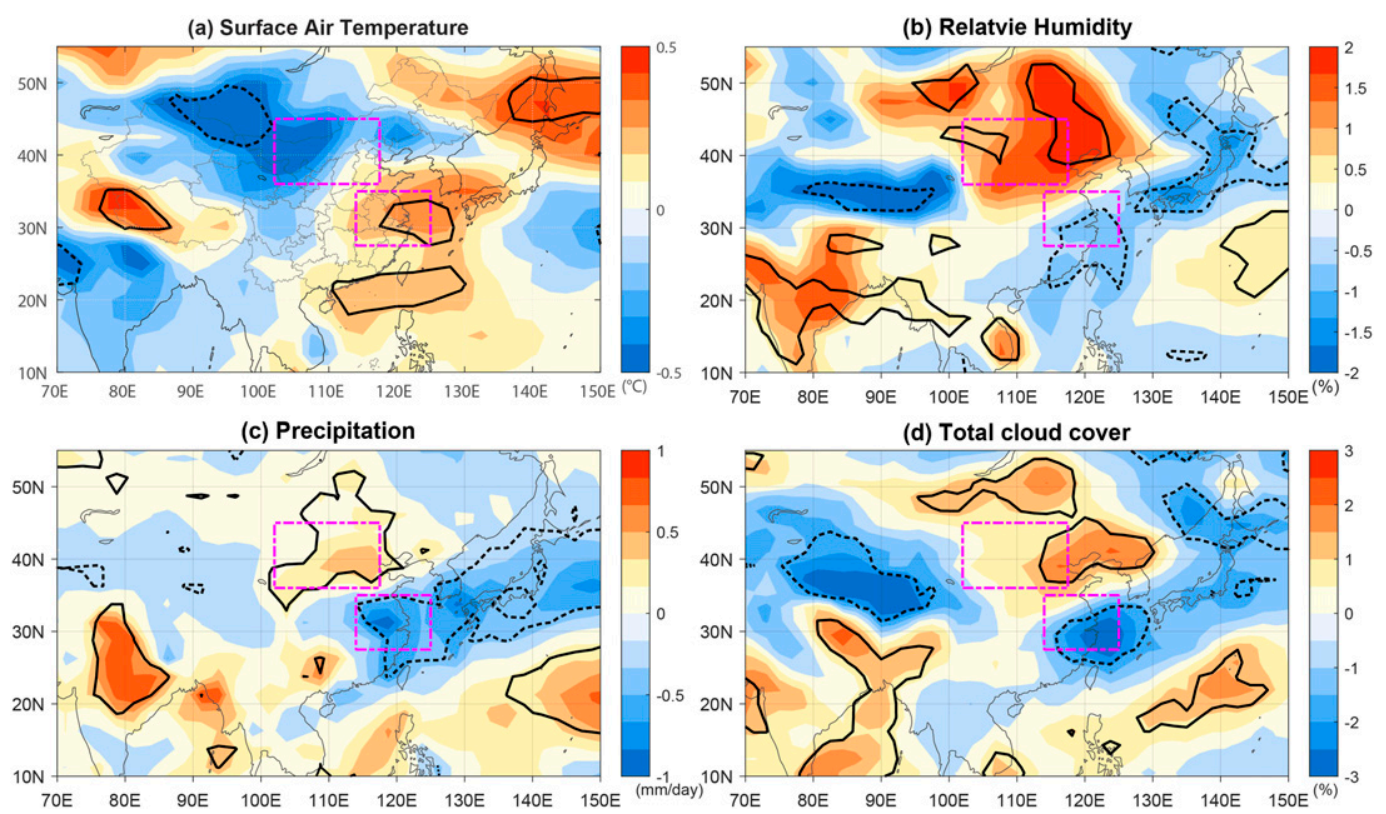

FIG. 5. Regression of the surface (a) 2-m air temperature, (b) relative humidity, (c) precipitation, and (d) total cloud cover onto the standardized PMM index. The purple boxes indicate the locations of eastern China and northern China. Solid and dashed contours respectively indicate positive and negative values significant at the 0.05 level based on 1000-times bootstrap sampling.

\section{b. Possible processes underlying the PMM-HTE association}

We now proceed to consider what large-scale atmospheric processes may be contributing to the PMM-HTE association. These atmospheric patterns are depicted by examining the regression coefficient of the related atmospheric variables upon the normalized PMM index for neutral ENSO years with low or no ENSO activity. Figures $5 \mathrm{a}$ and $5 \mathrm{~b}$ depict the patterns of surface air temperature and relative humidity associated with the PMM. The positive phase of PMM is coincident with warm temperature anomalies over eastern China and cool anomalies in northern China-Mongolia (Fig. 5a), corresponding to the strengthened and weakened HTE activity in these two areas, respectively (see also Fig. 2). The warming in the eastern part of China extends southward and covers many parts of southern China, in accord with the more frequent HTEs over the same region in the positive phase of the PMM (see Fig. 2a). The polarity of all of the above temperature anomalies would be reversed in the negative phase of the PMM. The surface relative humidity anomaly pattern (Fig. 5b) is generally opposite to that for surface air temperature. A positive PMM is accompanied by dry conditions over eastern China, Japan, and parts of central Asia, while increased humidity prevails over northern China, Mongolia, and India. The reductions in relative humidity over eastern
China correspond to the increased HTEs over that region (see Fig. 2a).

The regression map for precipitation is shown in Fig. 5c. Reduced precipitation is seen over eastern China and its adjacent oceans, in conjunction with enhanced HTE activity (Fig. 2a) and increased surface air temperature over these regions (Fig. 5a). In contrast, an increase in precipitation is noticeable over northern China (Fig. 5c). The change favors the cooling of the surface air temperature over northern China (Fig. 5a), thus suppressing the occurrence of HTEs in the region (Fig. 2a).

The regression patterns of 500-hPa geopotential height and vertical pressure velocity are presented in Fig. 6 . Positive height anomalies are seen over northeastern Asia and eastern China (Fig. 6a). Some of these sites are characterized by increased surface air temperatures (see Fig. 5a). Decreased heights are observed over northern China and Mongolia, which are coincident with cooler surface air temperature and weaker HTE activity (see Fig. 5a).

The positive (negative) geopotential height anomalies over eastern (northern) China are collocated with positive (negative) anomalies in pressure velocity (Fig. 6b). Over eastern China, the increased descending motion, in conjunction with decreased surface humidity and precipitation (see Figs. 5b,c), leads to enhanced HTE activity over that region (see Fig. 2). The descending motion is also conducive to reduced cloud cover (Fig. 5d), which favors increased 
(a) 500-hPa Geopotential Height

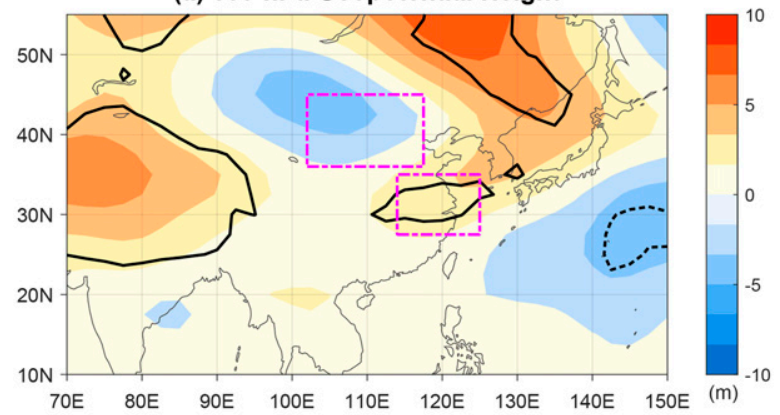

(b) $500-\mathrm{hPa}$ Vertical Velocity

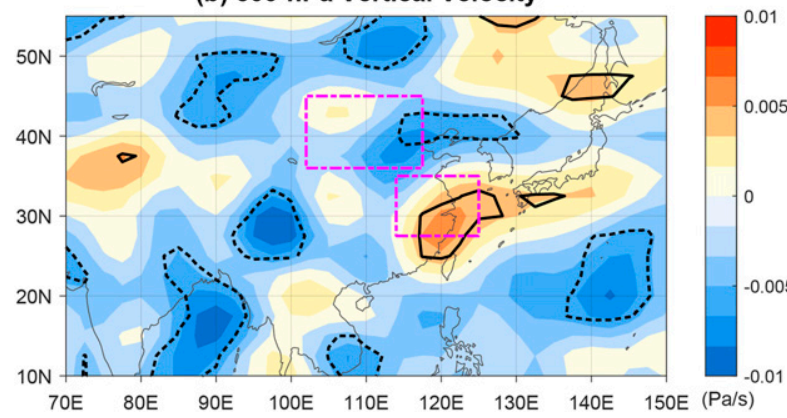

FIG. 6. As in Fig. 5, but for (a) 500-hPa geopotential height and (b) 500-hPa pressure velocity.

downward shortwave solar radiation to the surface (Fig. 7), thus promoting the onset and persistence of HTEs over eastern China. On the other hand, the prevalent anomalous ascent over northern China yields more precipitation, thus resulting in more cloud cover and surface cooling, and suppression of HTE activity there.

Figure 7 shows the regression patterns of the net shortwave and longwave radiation fluxes at the surface associated with the PMM. A positive value denotes an enhanced downward shortwave (Fig. 7a) or upward longwave radiation flux (Fig. $7 b$ ), whereas a negative one indicates weakened radiation flux. During positive PMM phases, descending motion over eastern China and the adjacent oceans is often accompanied by clear weather with less cloud formation (Fig. 5d); thus, more downward solar radiation reaches the surface of the area (Fig. 7a) and warms the surface there. As a result, the warming surface emits more upward longwave energy (Fig. 7b), heats the atmosphere near the surface, and favors HTE events in eastern China. The opposite changes in radiation can inhibit HTEs in northern China.

Figure 8 shows the horizontal winds at 850 - and $200-\mathrm{hPa}$ levels regressing onto the PMM index. During positive PMM phases, anomalous low-level anticyclonic circulation is observed over eastern China (Fig. 8a). The existence of this anticyclone is consistent with the decreased precipitation and sinking air motion (Figs. 5c and 6b), (a) Net Shortwave Radiation Flux

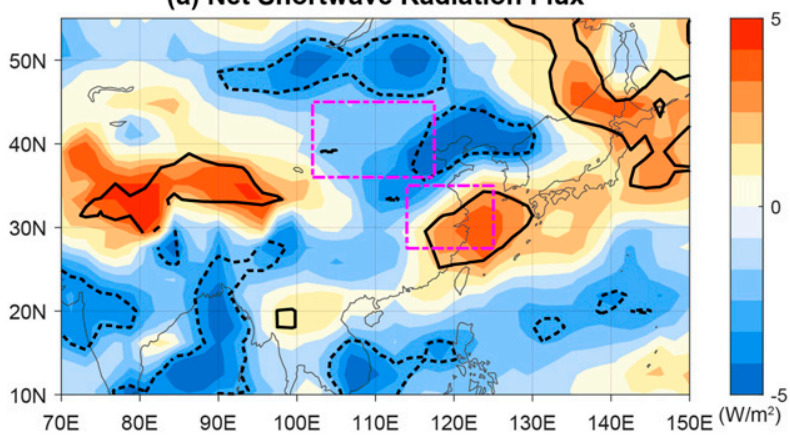

(b) Net Longwave Radiation Flux

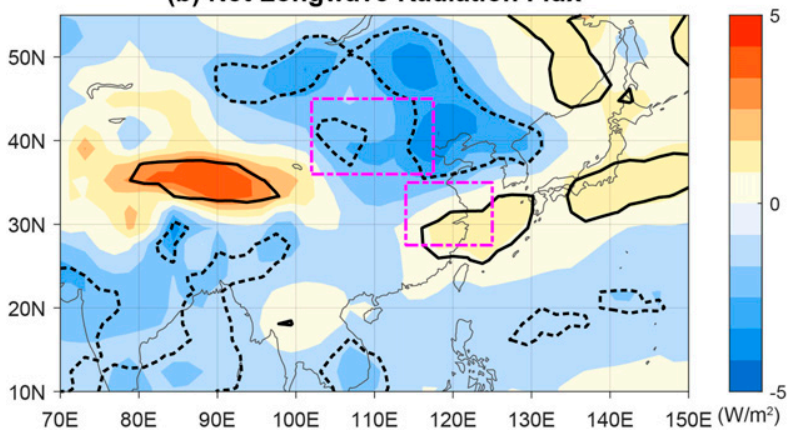

FIG. 7. As in Fig. 5, but for surface net (a) shortwave and (b) longwave radiation flux. Positive and negative values respectively denote enhanced and weakened downward shortwave or upward longwave radiation flux.

contributing to more frequent HTEs in eastern China. Noticeable cyclonic circulation anomalies appear over the WNP region $\left(10^{\circ}-30^{\circ} \mathrm{N}, 105^{\circ}-150^{\circ} \mathrm{E}\right)$ and over northern China and Mongolia. These cyclones correspond to increased precipitation and relatively cooler near-surface temperature there, thus leading to fewer HTEs over northern China. This cyclonic flow over the WNP has also been noticed by Zhang et al. (2016) and is associated with a Matsuno-Gill-type response to anomalous warming in the northwestern part of the PMM pattern. This circulation feature provides favorable conditions for tropical cyclone genesis in the WNP (Zhang et al. 2016).

At the upper level (Fig. 8b), anomalous anticyclones centering over northeastern Asia and the central Eurasian continent are discernible in the positive PMM phase. The anticyclones are accompanied by anomalous westerly flow over extratropical Asia (i.e., along $47.5^{\circ}-50^{\circ} \mathrm{N}$ ) and easterly flow over subtropical East Asia (i.e., along $30^{\circ}-35^{\circ} \mathrm{N}$ ). These patterns indicate that the prevalent subtropical westerly jet stream is weaker than normal in the positive PMM phase. In this environment of weaker jet stream intensity over the subtropics, the convective activity would decrease due to the weakened upper-tropospheric westerlies. As a result, precipitation would be suppressed and surface HTEs in eastern China would be more frequent. 
(a) 850-hPa Wind

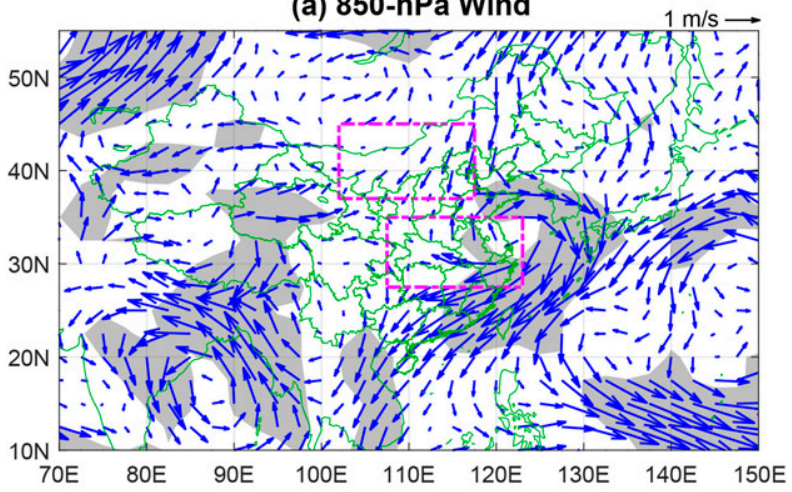

(b) 250-hPa Wind

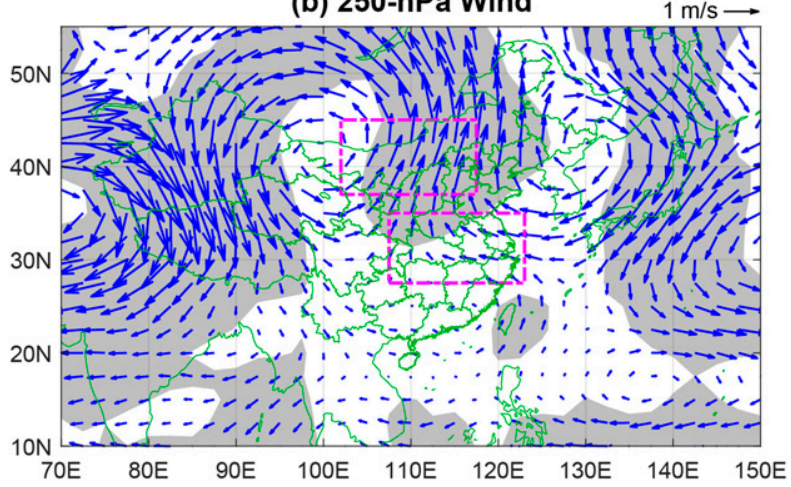

FIG. 8. As in Fig. 5, but for the (a) 850-hPa wind vectors and (b) 250-hPa wind vectors. Shading indicates significance for either the meridional or zonal component at the 0.05 level based on 1000 times bootstrap sampling.

The above results indicate prominent changes in geopotential height, the strength of the upper-level westerlies, precipitation, surface humidity, and lowerlevel flow patterns over eastern and northern China during opposing phases of the PMM. These changes favor (prohibit) the occurrence and intensification of HTEs over eastern (northern) China. We proceed to examine the physical mechanisms linking the PMM in the eastern subtropical North Pacific (ESTP) with the anomalous features over eastern and northern China.

As seen in Fig. 8a, an anomalous cyclone appears over the WNP region to the west of ESTP in the positive phase of PMM. This anomalous flow pattern is similar to the classic baroclinic Matsuno-Gill response of the lowlevel large-scale circulation to a heat source in the tropics (Gill 1980; Lee et al. 2009). The Matsuno-Gill-type response to deep convection related to SST warming during positive PMM phases has also been well reproduced in perturbation experiments with the high-resolution Geophysical Fluid Dynamics Laboratory (GFDL) Forecast-Oriented Low Ocean Resolution (FLOR) coupled climate model by Zhang et al. $(2016,2017)$ and
Gao et al. (2018). Also note that during the positive PMM phase, two symmetric cyclonic flow centers appear to the west of the PMM-related forcing, and an anticyclone appears on its east side (see Fig. 7 of Zhang et al. 2017). This response pattern implies that positive PMM may alter the large-scale circulation to both the west and east sides of ESTP. It may hence be argued that the PMM may exert remote influences on East Asian climate through both eastward and westward developments of response signals. The nature of these two classes of zonal developments will be further elaborated in the following discussion.

Through westward development, PMM-related heating forces an anomalous cyclonic flow pattern over the WNP and leads to an anomalous local meridional circulation that is characterized by ascending motion over the WNP and northern China and descending motion over eastern China [see Fig. $6 \mathrm{~b}$ in the present paper and Fig. 7 of Zhang et al. (2017)]. As a result, precipitation increases in the WNP and northern China and decreases in eastern China during positive PMM summers (Fig. 5c). These changes provide favorable (unfavorable) environments for the occurrence of HTEs in eastern (northern) China.

In regard to eastward development of circulation anomalies, it is noted that the PMM forces an eastwardpropagating Rossby wave along the westerlies in the upper atmosphere, similar to the stationary Rossby wave train excited by tropical SST heating anomalies (Lee et al. 2009). Figure 9a displays the regression map of $250-\mathrm{hPa}$ wind fields over the entire Northern Hemisphere (NH), whereas the regression map of geopotential height is shown in Fig. $9 \mathrm{~b}$ using color shading. The patterns show a distinct wavelike structure over the subtropics of $\mathrm{NH}$. This wave structure in the regression maps is consistent with the high and low centers of the circumglobal teleconnection (CGT) pattern, which corresponds to the second leading empirical orthogonal function of the interannual variability of the upper-tropospheric circulation over NH midlatitudes (Ding and Wang 2005). We also notice that the PMM shows a significant correlation of $0.31(p<$ 0.05 ) with the summer CGT index, which is defined as the areal mean of the $200-\mathrm{hPa}$ geopotential height averaged over $35^{\circ}-40^{\circ} \mathrm{N}, 60^{\circ}-70^{\circ} \mathrm{E}$ (Ding and Wang 2005). These results suggest that the SST gradient pattern in eastern subtropical North Pacific (i.e., warming in the northwest and cooling in the southeast of eastern subtropical North Pacific; see Fig. 1) can trigger a propagation of Rossby wave over the NH midlatitudes (Fig. 9b).

The propagation of the Rossby wave related to PMM is also supported by the regression maps of stationary WAF (vectors in Fig. 9b). WAF over the midlatitudes of the NH exhibits an eastward wave path from the eastern subtropical North Pacific to East Asia and is modulated by the westerly jet stream. Through this far-reaching zonal 
(a) 250-hPa Wind

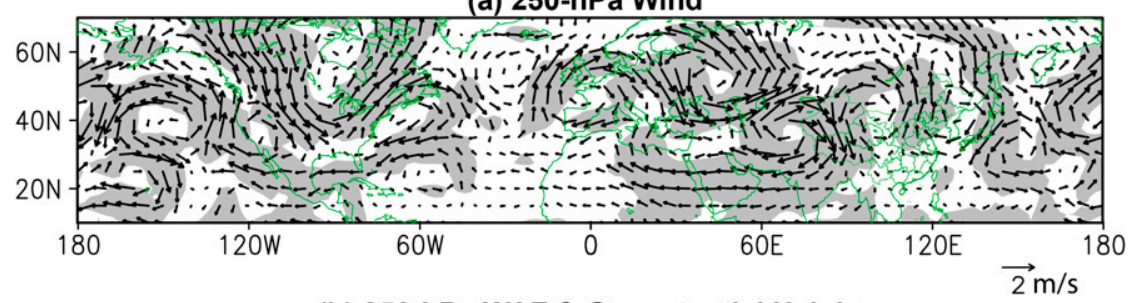

(b) 250-hPa WAF \& Geopotential Height

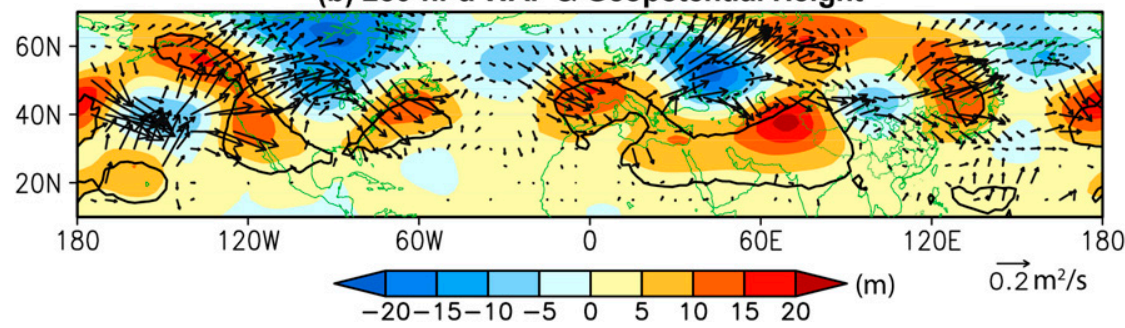

FIG. 9. As in Fig. 5, but for (a) wind (vectors) and (b) geopotential height (shading) and horizontal wave activity flux (WAF; vectors) at the $250-\mathrm{hPa}$ level. Shading in (a) indicates significance for either the meridional or zonal component at the 0.05 level based on 1000-times bootstrap sampling. The solid and dashed contours in (b) respectively denote positive and negative geopotential height differences that are significant at the 0.05 level. For WAF, only those vectors that are significant at the 0.05 level are plotted.

teleconnection, a positive PMM is associated with anomalously enhanced geopotential high and anticyclone in the upper troposphere over East Asia (Fig. 9a). These features are accompanied by anomalously downward air motion and reduced precipitation over eastern China (Figs. $6 \mathrm{~b}$ and 5c), as well as an anticyclone near the surface (Fig. 8a), thus providing favorable conditions for enhancing HTE activity in this area. Under the influences of the CGT-like wave chain, northern China is covered by anomalous ascending air motion and enhanced precipitation, as well as a cyclone at the lower atmosphere. These changes tend to inhibit HTE activity in northern China.

The observed wave train associated with PMM, as depicted using reanalysis data (Fig. 9), is also well reproduced in a set of AGCM experiments with the ECHAM5 model, as analyzed by $\mathrm{Li}$ et al. (2011) (see their Fig. 12c). These experiments entail the prescription of SST forcing in ESTP, where the PMM is associated with the strongest SST variations (Chiang and Vimont 2004). As shown in Fig. 12c of Li et al. (2011), positive SST anomalies in ESTP induce a zonal wave pattern over the midlatitudes of the NH. This pattern exhibits positive 300-hPa geopotential height anomalies over the eastern North Pacific, the western North Atlantic, western Europe, and the eastern China-western Pacific region. These modeling results on $300-\mathrm{hPa}$ geopotential height responses to ESTP SST forcing are in overall agreement with the regression of geopotential height and stationary WAF onto the PMM index in the present study (see Fig. 9). This comparison further demonstrates that the PMM may contribute to the characteristic flow pattern associated with HTE activity in China by triggering a CGT-like Rossby wave teleconnection pattern. Also, Li et al. (2011) suggested that anomalous heating associated with the shift of the mean intertropical convergence zone (ITCZ) induced by the ESTP SST variability can generate eastward Rossby wave trains, with remote influences on the East Asian region.

\section{Summary}

Although the intensifying trends in hot extremes in many parts of the world have been well documented in many previous studies, their variability has not been fully understood. In the current study, we investigate the association between PMM and summer HTEs in China at the interannual scale. Our results show that the positive (negative) PMM phase promotes (suppresses) the occurrence of HTEs in eastern China, and suppresses (promotes) the HTEs in northern China. This PMMHTE association seems to be independent of ENSO events, indicating that the variability of PMM has potential value for the prediction of HTE activity.

Our results further indicate that the PMM can exert remote influences on the summer climate in faraway East Asia through both eastward and westward developments of circulation changes. In regard to westward development, PMM-related heating forces an anomalous cyclone over the WNP via the Matsuno-Gill-type response, which is in turn associated with an anomalous 


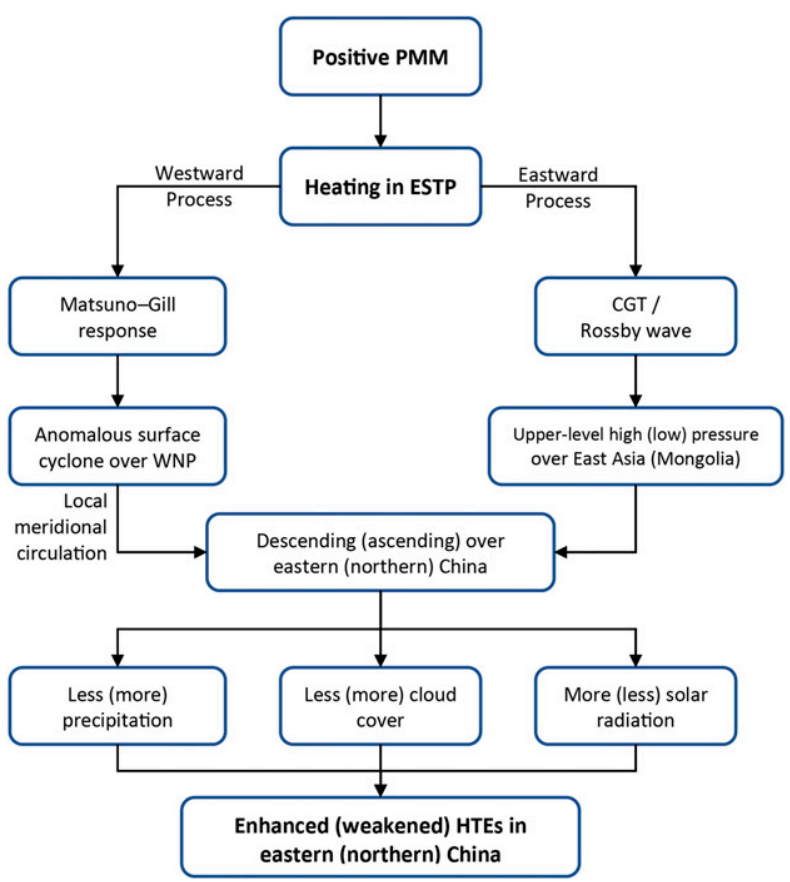

FIG. 10. A conceptual schematic showing the possible processes underlying the linkage between a positive PMM pattern and enhanced (weakened) HTEs in eastern (northern) China.

local meridional circulation. The latter circulation is characterized by ascending motions over the WNP and northern China, and subsidence over eastern China. In regard to eastward development, PMM generates a Rossby wave train at the upper level over the midlatitudes of NH. This wave train extends from the eastern subtropical North Pacific to the Eurasian continent and is embedded in the circumpolar westerly jet stream. In the positive PMM phase, anomalous high geopotential height and an anticyclonic circulation center appear in the upper troposphere over East Asia, whereas anomalous cyclonic flows and lowered geopotential height are seen to prevail over Mongolia and northern China. These patterns bear some resemblance to the characteristics of the CGT over East Asia. In summary, the anomalous surface anticyclone, subsidence (which results in adiabatic warming), and reduced precipitation collectively support an environment that is conducive to enhanced HTE activity over eastern China when PMM is in its positive phase. Conversely, opposite circulation changes over northern China during a positive PMM are accompanied by reduced local HTE occurrences. The myriad processes linking the PMM and HTE activity in East Asia are depicted in the flowchart in Fig. 10.

We have evaluated the sensitivity of our results to different selections of the thresholds for identifying HTEs, by using the 95th and 99th percentiles. The

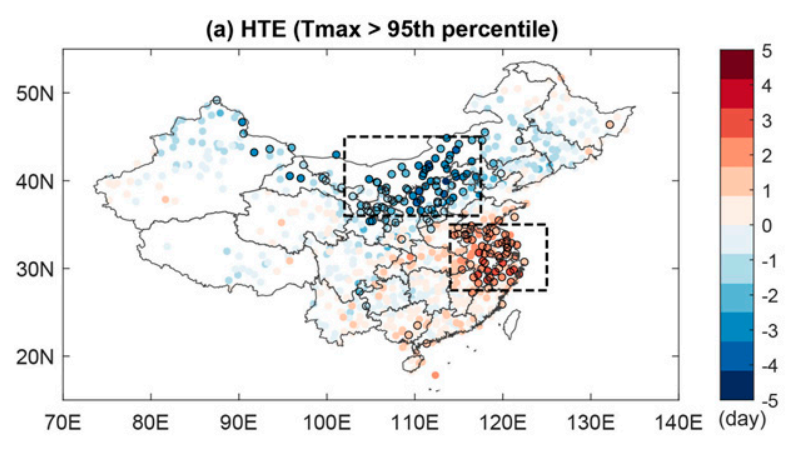

(b) HTE (Tmax > 99th percentile)

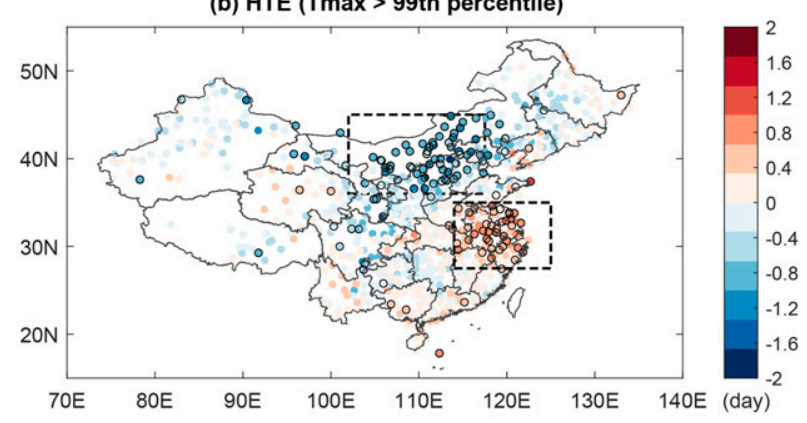

FIG. 11. As in Fig. 2a, but for the HTEs based on the (a) 95th- and (b) 99th-percentile thresholds.

results are shown in Fig. 11. Different thresholds yield some differences in the magnitude of the regression coefficients versus the PMM index. However, the spatial distributions are quite similar to that based on the 90th percentile (see Fig. 2a). A positive PMM is associated with more frequent HTEs in eastern China and less frequent HTEs in northern China. These robust findings enhance our confidence in the results presented in this study.

The analyses performed in this study are based on station-based observations and reanalysis datasets. It is also of great interest to examine in more detail the association between PMM and summer climate in China or a larger East Asian domain in model simulations. Our study provides some hints as to the impacts of the PMM on summer extreme weather in China. Previous studies suggested that the PMM may be linked to the development of ENSO events. Such interactions between the PMM and ENSO could be affected by changes in the climatological background of the atmosphere-ocean coupled system. These complex issues have yet to be fully understood and call for further investigations.

Acknowledgments. This study is partially funded by the National Natural Science Foundation of China (Grants 41871029 and 41401052) and the National Science Foundation for Distinguished Young Scholars of China (Grant 51425903). The appointment of M. Luo at Sun Yat-sen University is partially supported by the 
Pearl River Talent Recruitment Program of Guangdong Province, China (2017GC010634). We acknowledge the China Meteorological Data Service Center for sharing the daily temperature observations in China (available at https://data.cma.cn/), and NOAA Earth System Research Laboratory for providing the NCEP-NCAR Reanalysis1 dataset (https://www.esrl.noaa.gov/psd/data/gridded/data. ncep.reanalysis.html) and the PMM index (at https:// www.esrl.noaa.gov/psd/data/timeseries/monthly/PMM/). The authors are thankful to two anonymous reviewers for their valuable comments and suggestions on improving our paper.

\section{REFERENCES}

Alexander, L., and Coauthors, 2006: Global observed changes in daily climate extremes of temperature and precipitation. J. Geophys. Res., 111, D05109, https://doi.org/10.1029/2005JD006290.

Amaya, D. J., 2019: The Pacific meridional mode and ENSO: A review. Curr. Climate Change Rep., 5, 296-307, https://doi.org/ 10.1007/s40641-019-00142-x.

Chan, J. C. L., 2000: Tropical cyclone activity over the western North Pacific associated with El Niño and La Niña events. J. Climate, 13, 2960-2972, https://doi.org/10.1175/1520-0442(2000) 013<2960:TCAOTW>2.0.CO;2.

Chang, C., Y. Zhang, and T. Li, 2000: Interannual and interdecadal variations of the East Asian summer monsoon and tropical Pacific SSTs. Part I: Roles of the subtropical ridge. J. Climate, 13, 4310-4325, https://doi.org/10.1175/1520-0442(2000)013<4310: IAIVOT $>2.0 . \mathrm{CO} ; 2$.

Chang, P., L. Zhang, R. Saravanan, D. J. Vimont, J. C. H. Chiang, L. Ji, H. Seidel, and M. K. Tippett, 2007: Pacific meridional mode and El Niño-Southern Oscillation. Geophys. Res. Lett., 34, L16608, https://doi.org/10.1029/2007GL030302.

Chen, M., P. Xie, J. E. Janowiak, and P. A. Arkin, 2002: Global land precipitation: A 50-yr monthly analysis based on gauge observations. J. Hydrometeor., 3, 249-266, https://doi.org/ 10.1175/1525-7541(2002)003<0249:GLPAYM>2.0.CO;2.

Chen, R., Z. Wen, and R. Lu, 2018: Large-scale circulation anomalies and intraseasonal oscillations associated with longlived extreme heat events in South China. J. Climate, 31, 213232, https://doi.org/10.1175/JCLI-D-17-0232.1.

Chiang, J. C. H., and D. J. Vimont, 2004: Analogous Pacific and Atlantic meridional modes of tropical atmosphere-ocean variability. J. Climate, 17, 4143-4158, https://doi.org/10.1175/ JCLI4953.1.

Di Lorenzo, E., G. Liguori, N. Schneider, J. C. Furtado, B. T. Anderson, and M. A. Alexander, 2015: ENSO and meridional modes: A null hypothesis for Pacific climate variability. Geophys. Res. Lett., 42, 9440-9448, https://doi.org/10.1002/2015GL066281.

Ding, Q., and B. Wang, 2005: Circumglobal teleconnection in the Northern Hemisphere summer. J. Climate, 18, 3483-3505, https://doi.org/10.1175/JCLI3473.1.

Ding, R., J. Li, Y.-h. Tseng, C. Sun, Y. Li, N. Xing, and X. Li, 2019: Linking the North American dipole to the Pacific meridional mode. J. Geophys. Res. Atmos., 124, 3020-3034, https:// doi.org/10.1029/2018JD029692.

Ding, T., W. Qian, and Z. Yan, 2010: Changes in hot days and heat waves in China during 1961-2007. Int. J. Climatol., 30, 14521462,https://doi.org/10.1002/JOC.1989.
Donat, M. G., and Coauthors, 2013: Updated analyses of temperature and precipitation extreme indices since the beginning of the twentieth century: The HadEX2 dataset. J. Geophys. Res. Atmos., 118, 2098-2118, https://doi.org/10.1002/JGRD.50150.

Duchon, C. E., 1979: Lanczos filtering in one and two dimensions. J. Appl. Meteor., 18, 1016-1022, https://doi.org/10.1175/15200450(1979)018<1016:LFIOAT > 2.0.CO;2.

Efron, B., and R. J. Tibshirani, 1994: An Introduction to the Bootstrap. CRC Press, 456 pp.

Fischer, E. M., and R. Knutti, 2015: Anthropogenic contribution to global occurrence of heavy-precipitation and high-temperature extremes. Nat. Climate Change, 5, 560-564, https://doi.org/ 10.1038/nclimate2617.

Freychet, N., S. Tett, J. Wang, and G. Hegerl, 2017: Summer heat waves over eastern China: Dynamical processes and trend attribution. Environ. Res. Lett., 12, 024015, https://doi.org/ 10.1088/1748-9326/aa5ba3.

Gao, S., L. Zhu, W. Zhang, and Z. Chen, 2018: Strong modulation of the Pacific meridional mode on the occurrence of intense tropical cyclones over the western North Pacific. J. Climate, 31, 7739-7749, https://doi.org/10.1175/JCLI-D-17-0833.1.

Gao, T., Q. Zhang, and M. Luo, 2020a: Intensifying effects of El Niño events on winter precipitation extremes in southeastern China. Climate Dyn., 54, 631-648, https://doi.org/10.1007/ s00382-019-05022-6.

_ - M. Luo, N.-C. Lau, and T. O. Chan, 2020b: Spatially distinct effects of two El Niño types on summer heat extremes in China. Geophys. Res. Lett., 47, e2020GL086982, https:// doi.org/10.1029/2020GL086982.

Gill, A. E., 1980: Some simple solutions for heat-induced tropical circulation. Quart. J. Roy. Meteor. Soc., 106, 447-462, https:// doi.org/10.1002/qj.49710644905.

Hu, K., G. Huang, X. Qu, and R. Huang, 2012: The impact of Indian Ocean variability on high temperature extremes across the southern Yangtze River valley in late summer. $A d v$. Atmos. Sci., 29, 91-100, https://doi.org/10.1007/s00376-0110209-2.

, -, and R. Wu, 2013: A strengthened influence of ENSO on August high temperature extremes over the southern Yangtze River valley since the late 1980s. J. Climate, 26, 2205-2221, https://doi.org/10.1175/JCLI-D-12-00277.1.

IPCC, 2012: Managing the Risks of Extreme Events and Disasters to Advance Climate Change Adaptation: Special Report of the Intergovernmental Panel on Climate Change. Cambridge University Press, $582 \mathrm{pp}$.

_ 2013: Climate Change 2013: The Physical Science Basis. T. F. Stocker et al., Eds., Cambridge University Press, 1535 pp., https://doi.org/10.1017/CBO9781107415324.

Japan Meteorological Agency, 2013: JRA-55: Japanese 55-year Reanalysis, monthly means and variances. Research Data Archive at the National Center for Atmospheric Research, Computational and Information Systems Laboratory, https:// doi.org/10.5065/D60G3H5B.

Kalnay, E., and Coauthors, 1996: The NCEP/NCAR 40-Year Reanalysis Project. Bull. Amer. Meteor. Soc., 77, 437-471, https:// doi.org/10.1175/1520-0477(1996)077<0437:TNYRP>2.0.CO;2.

Kobayashi, S., and Coauthors, 2015: The JRA-55 Reanalysis: General specifications and basic characteristics. J. Meteor Soc. Japan, 93, 5-48, https://doi.org/10.2151/jmsj.2015-001.

Larson, S. M., and B. P. Kirtman, 2014: The Pacific meridional mode as an ENSO precursor and predictor in the North American multimodel ensemble. J. Climate, 27, 7018-7032, https://doi.org/10.1175/JCLI-D-14-00055.1. 
Lau, N.-C., and M. J. Nath, 2006: ENSO modulation of the interannual and intraseasonal variability of the East Asian monsoon-A model study. J. Climate, 19, 4508-4530, https://doi.org/10.1175/JCLI3878.1.

Lee, S.-K., C. Wang, and B. E. Mapes, 2009: A simple atmospheric model of the local and teleconnection responses to tropical heating anomalies. J. Climate, 22, 272-284, https://doi.org/10.1175/2008JCLI2303.1.

Li, C., L. Wu, and P. Chang, 2011: A far-reaching footprint of the tropical Pacific meridional mode on the summer rainfall over the Yellow River loop valley. J. Climate, 24, 2585-2598, https://doi.org/10.1175/2010JCLI3844.1.

Li, H., A. Dai, T. Zhou, and J. Lu, 2010: Responses of East Asian summer monsoon to historical SST and atmospheric forcing during 1950-2000. Climate Dyn., 34, 501-514, https://doi.org/ 10.1007/s00382-008-0482-7.

Lu, R.-Y., and R.-D. Chen, 2016: A review of recent studies on extreme heat in China. Atmos. Oceanic Sci. Lett., 9, 114-121, https://doi.org/10.1080/16742834.2016.1133071.

Luo, M., and N.-C. Lau, 2017: Heat waves in Southern China: Synoptic behavior, long-term change, and urbanization effects. J. Climate, 30, 703-720, https://doi.org/10.1175/JCLI-D-16-0269.1.

— and - 2018: Amplifying effect of ENSO on heat waves in China. Climate Dyn., 52, 3277-3289, https://doi.org/10.1007/ s00382-018-4322-0.

$\longrightarrow$, and - 2020: Summer heat extremes in northern continents linked to developing ENSO events. Environ. Res. Lett. https://doi.org/10.1088/1748-9326/ab7d07, in press.

Ma, J., S.-P. Xie, and H. Xu, 2017: Contributions of the North Pacific meridional mode to ensemble spread of ENSO prediction. J. Climate, 30, 9167-9181, https://doi.org/10.1175/JCLI-D-17-0182.1.

Meehl, G. A., and C. Tebaldi, 2004: More intense, more frequent, and longer lasting heat waves in the 21 st century. Science, $\mathbf{3 0 5}$, 994-997, https://doi.org/10.1126/science.1098704.

Min, Q., J. Su, and R. Zhang, 2017: Impact of the South and North Pacific meridional modes on the El Niño-Southern Oscillation: Observational analysis and comparison. J. Climate, 30,1705-1720, https://doi.org/10.1175/JCLI-D-16-0063.1.

Rayner, N. A., D. E. Parker, E. B. Horton, C. K. Folland, L. V. Alexander, D. P. Rowell, E. C. Kent, and A. Kaplan, 2003: Global analyses of sea surface temperature, sea ice, and night marine air temperature since the late nineteenth century. J. Geophys. Res., 108, 4407, https://doi.org/10.1029/2002JD002670.

Rogers, J. C., 1981: The North Pacific Oscillation. Int. J. Climatol., 1, 39-57, https://doi.org/10.1002/joc.3370010106.

Stuecker, M. F., 2018: Revisiting the Pacific meridional mode. Sci. Rep., 8, 3216, https://doi.org/10.1038/s41598-018-21537-0.

Takaya, K., and H. Nakamura, 2001: A formulation of a phaseindependent wave-activity flux for stationary and migratory quasigeostrophic eddies on a zonally varying basic flow. J. Atmos. Sci., 58, 608-627, https://doi.org/10.1175/15200469(2001)058<0608:AFOAPI > 2.0.CO;2.

Thomas, E. E., and D. J. Vimont, 2016: Modeling the mechanisms of linear and nonlinear ENSO responses to the Pacific meridional mode. J. Climate, 29, 8745-8761, https://doi.org/ 10.1175/JCLI-D-16-0090.1.

Trenberth, K. E., 1997: The definition of El Niño. Bull. Amer. Meteor. Soc., 78, 2771-2777, https://doi.org/10.1175/15200477(1997)078<2771:TDOENO > 2.0.CO;2.

Walker, G. T., and E. W. Bliss, 1932: World weather V. Mem Roy Meteor. Soc., 4, 53-84.

Wang, B., R. G. Wu, and X. H. Fu, 2000: Pacific-East Asian teleconnection: How does ENSO affect East Asian climate?
J. Climate, 13, 1517-1536, https://doi.org/10.1175/1520-0442(2000) 013<1517:PEATHD $>2.0$. CO; 2 .

Wang, W., W. Zhou, X. Wang, S. K. Fong, and K. C. Leong, 2013: Summer high temperature extremes in southeast China associated with the East Asian jet stream and circumglobal teleconnection. J. Geophys. Res. Atmos., 118, 8306-8319, https:// doi.org/10.1002/JGRD.50633.

- — - and D. Chen, 2014: Summer high temperature extremes in southeast China: Bonding with the El Niño-Southern Oscillation and East Asian summer monsoon coupled system. J. Climate, 27, 4122-4138, https://doi.org/10.1175/JCLI-D-13-00545.1.

Wu, R., and B. Wang, 2002: A contrast of the East Asian summer monsoon-ENSO relationship between 1962-77 and 1978-93. J. Climate, 15, 3266-3279, https://doi.org/10.1175/1520-0442(2002) 015<3266:ACOTEA > 2.0.CO;2.

Xie, S.-P., Y. Du, G. Huang, X.-T. Zheng, H. Tokinaga, K. Hu, and Q. Liu, 2010: Decadal shift in El Niño influences on Indowestern Pacific and East Asian climate in the 1970s. J. Climate, 23, 3352-3368, https://doi.org/10.1175/2010JCLI3429.1.

Xu, W., Q. Li, X. L. Wang, S. Yang, L. Cao, and Y. Feng, 2013: Homogenization of Chinese daily surface air temperatures and analysis of trends in the extreme temperature indices. J. Geophys. Res. Atmos., 118, 9708-9720, https://doi.org/10.1002/JGRD.50791.

Yang, X., R. L. Leung, N. Zhao, C. Zhao, Y. Qian, K. Hu, X. Liu, and B. Chen, 2017: Contribution of urbanization to the increase of extreme heat events in an urban agglomeration in east China. Geophys. Res. Lett., 44, 6940-6950, https://doi.org/ 10.1002/2017GL074084.

You, Q., Z. Jiang, L. Kong, Z. Wu, Y. Bao, S. Kang, and N. Pepin, 2017: A comparison of heat wave climatologies and trends in China based on multiple definitions. Climate Dyn., 48, 39753989, https://doi.org/10.1007/s00382-016-3315-0.

Zhai, P., and X. Pan, 2003: Trends in temperature extremes during 1951-1999 in China. Geophys. Res. Lett., 30, 1913, https:// doi.org/10.1029/2003GL018004.

Zhang, H., A. Clement, and P. D. Nezio, 2014a: The South Pacific meridional mode: A mechanism for ENSO-like variability. J. Climate, 27, 769-783, https://doi.org/10.1175/JCLI-D-13-00082.1.

_ C. Deser, A. Clement, and R. Tomas, 2014b: Equatorial signatures of the Pacific meridional modes: Dependence on mean climate state. Geophys. Res. Lett., 41, 568-574, https:// doi.org/10.1002/2013GL058842.

Zhang, L., P. Chang, and L. Ji, 2009: Linking the Pacific meridional mode to ENSO: Coupled model analysis. J. Climate, 22, 34883505, https://doi.org/10.1175/2008JCLI2473.1.

Zhang, W., G. A. Vecchi, H. Murakami, G. Villarini, and L. Jia, 2016: The Pacific meridional mode and the occurrence of tropical cyclones in the western North Pacific. J. Climate, 29, 381-398, https://doi.org/10.1175/JCLI-D-15-0282.1.

— , G. Villarini, and G. A. Vecchi, 2017: Impacts of the Pacific meridional mode on June-August precipitation in the Amazon river basin. Quart. J. Roy. Meteor. Soc., 143, 1936-1945, https:// doi.org/10.1002/qj.3053.

Zhou, B., Y. Xu, J. Wu, S. Dong, and Y. Shi, 2016: Changes in temperature and precipitation extreme indices over China: Analysis of a high-resolution grid dataset. Int. J. Climatol., 36, 1051-1066, https://doi.org/10.1002/joc. 4400.

Zhou, W., and J. C. Chan, 2007: ENSO and the South China Sea summer monsoon onset. Int. J. Climatol., 27, 157-167, https:// doi.org/10.1002/joc.1380.

Zhou, Y., and G. Ren, 2011: Change in extreme temperature event frequency over mainland China, 1961-2008. Climate Res., 50, 125139, https://doi.org/10.3354/cr01053. 